\title{
MEME KANSERINDE MOLEKÜLER ALT TIPLERIN KLINIKOPATOLOJIK ÖZELLIKLERLE iLIŞKISi
}

\author{
THE RELATIONSHIP OF THE MOLECULAR SUBTYPES WITH THE
} CLINICOPATHOLOGICAL FEATURES IN BREAST CANCER

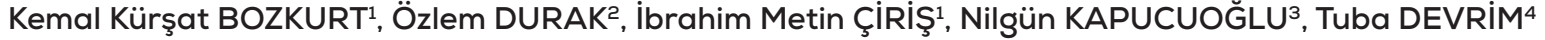 \\ ${ }^{1}$ Süleyman Demirel Üniversitesi Tıp Fakültesi Tıbbi Patoloji Anabilim Dalı, Isparta, Türkiye. \\ ${ }^{2}$ T.C. Sağ Iık Bak. Kamu Hastaneler Birliği Kastamonu Devlet Hast. Tibbi Patoloji Bölümü, Kastamonu, Türkiye. \\ ${ }^{3}$ Koç Üniversitesi Tıp Fakültesi Tıbbi Patoloji Anabilim Dalı, İstanbul, Türkiye. \\ ${ }^{4}$ Kırıkkale Üniversitesi Tıp Fakültesi Tıbbi Patoloji Anabilim Dalı, Kırıkkale, Türkiye
} Cite this article as: Bozkurt KK, Durak Ö, Çiriş IM, Kapucuoğlu N, Devrim T. The relationship of the molecular subtypes with the
clinicopathological features in breast cancer. Med J SDU 2020; 27(2): 160-165.

\section{Öz}

\section{Amaç}

Meme kanserinde, moleküler alt tiplerin, klinikopatolojik özellikler (tanı yaşı, histolojik tip, histolojik derece, $\mathrm{pT}$ ve $\mathrm{pN}$ evreleri) ile ilişkilerinin tespit edilmesi amaçlanmıştır.

\section{Gereç ve Yöntem}

Çalışma grubu 194 kadın meme kanseri içermekteydi. Süleyman Demirel Üniversitesi Tıp Fakültesi Tıbbi Patoloji Anabilim Dalı arşivi taranarak 2010-2015 yılları arasında meme kanseri tanısı verilmiş olgulara ait biyopsi ve radikal meme rezeksiyonu materyallerinin preparatları tekrar incelendi. Olguların immünhistokimyasal ER, PgR, HER2 ve Ki67 boyalı preparatları tekrar değerlendirilerek moleküler alt tiplendirme yapıldı.

\section{Bulgular}

Tümör moleküler alt tipleri; $\% 47,4$ olguda Luminal A [ER ve/veya PgR(+)/HER2(-)/Ki67 $\leq \% 14], \% 25,8$ olguda Luminal B [ER ve/veya PgR(+)/HER2(+) veya (-) /Ki67 > \%14], \%13,4 olguda HER2 overeksprese $[\mathrm{ER}(-) / \mathrm{PgR}(-) / \mathrm{HER} 2(+)]$ ve $\% 13,4$ olguda ise üçlü negatif $[\mathrm{ER}(-) / \mathrm{PgR}(-) / \mathrm{HER} 2(-)]$ idi. Tümör derecesi ve aksiller lenf nodu metastazı; Luminal B, HER2 overeksprese ve üçlü negatif tümörlerde Luminal $A$ tümörlere göre daha yüksek izlendi. Luminal tip tümörlerle karşılaştııllığında, HER2 overeksprese ve üçlü negatif tümörlerde lenfovasküler invazyon oranı anlamlı olarak daha fazla idi.

\section{Sonuç}

Heterojen bir tümör grubu olan meme kanserlerinde evre ve diğer iyi bilinen klinikopatolojik özelliklerin yanında moleküler alt tiplendirmenin de hasta yönetimi için faydalı bilgiler verebileceği sonucuna varılmıştır.

Anahtar Kelimeler: Meme, kanser, moleküler alt tip, immünhistokimya

\section{Abstract}

\section{Objective}

To determine the relationship between the molecular subtypes and the clinicalopathological features (age at the diagnosis, histological type, histological grade, pT and pN stages) in breast cancer.

\section{Materials and Methods}

The study population included 194 women with breast carcinoma, who were diagnosed between 2010 and 2015. The slides of the cases in the archive of the Süleyman Demirel University Faculty of Medicine Department of Pathology were reevaluated. Immunohis-

İletişim kurulacak yazar/Corresponding author: kemalbozkurt@sdu.edu.tr

Müracaat tarihi/Application Date: 15.08.2019 • Kabul tarihi/Accepted Date: 03.09.2019

Available online at http://dergipark.gov.tr/sdutfd

Makaleye http://dergipark.gov.tr/sdutfd web sayfasından ulaşılabilir. 
tochemical ER, PgR, HER2 and Ki67 stained slides were used to perform the molecular subtyping.

\section{Results}

Among the cases molecular subtypes were; Luminal A [ER and/or PgR(+)/HER2(-)/Ki67 $\leq 14 \%]$ in $47.4 \%$ of cases, Luminal B [ER and/or PgR(+)/HER2(+) or $(-) /$ Ki67 $>14 \%]$ in $25.8 \%$ of cases, HER2 overexpressing $[\mathrm{ER}(-) / \mathrm{PgR}(-) / \mathrm{HER} 2(+)]$ in $13.4 \%$ of cases, and triple negative $[\mathrm{ER}(-) / \mathrm{PgR}(-) / \mathrm{HER} 2(-)]$ in $13.4 \%$ of the cases, respectively. Tumor grade and axillary lymph node metastasis in Luminal B, HER2 overexpressing and triple negative tumors were significantly higher than they were in Luminal A tumors. Lymphovascular invasion rate was significantly higher in HER2 overexpressing and triple negative tumors compared to Luminal type tumors.

\section{Conclusions}

It was concluded that the molecular subtyping of the breast carcinoma, which is a heterogeneous tumor group, can give important information for the management of the cases along with the stage and other well-known clinicopathological features.

Keywords: Breast, cancer, molecular subtype, immunohistochemistry.

\section{Giriş}

Meme kanseri, dünya çapında kadınlar arasında kanser ölümünün önde gelen nedeni olmaya devam etmekte ve geleneksel tedaviler yıllarca süren araştırmalara rağmen yetersiz kalmaktadır (1). Meme kanserli hastaların prognozu ve yönetimi, histolojik tip ve derece gibi klasik parametrelerle ilişkili olup, tümör büyüklüğü, lenf nodu tutulumu ve tümörün östrojen reseptörü (ER), progesteron reseptörü $(\mathrm{PgR})$ ve insan epidermal büyüme faktörü reseptörü 2 (HER2) düzeyleri de prognozu etkileyen diğer faktörler arasında yer almaktadır (2).

Son yıllarda, genlerin ekspresyon profillerini inceleyen çalışmalar sayesinde, meme kanseri biyolojisinin daha iyi anlaşılması sağlanmaktadır. Bu kapsamda, meme kanserinin 5 moleküler alt tipi (Luminal A, Luminal B, HER2 overeksprese, Bazal benzeri ve Claudin-düşük) tanımlanmıştır (3). Ayrıca Claudin-düşük tümörlerin tercihen triple-negatif bir fenotip gösterdiği belirlenmiş olup sadece triple-negatif meme kanserlerinin (TNMK) çok az bir kısmında claudin-düşük alt tipinin bulunduğu saptanmıştır (4). Bu çalışmada, meme kanseri moleküler alt tiplerinin immünhistokimya kullanılarak belirlenmesi ve bu alt tiplerin klinikopatolojik özelliklerle ilişkisinin irdelenmesi amaçlandı.

\section{Gereç ve Yöntem}

Çalışmamız kapsamında Süleyman Demirel Üniversitesi Tıp Fakültesi Tıbbi Patoloji Anabilim Dalı arşivi taranarak 2010-2015 yılları arasında meme kanseri tanısı verilmiş biyopsi ve radikal meme rezeksiyonu materyallerine ait patoloji raporları incelenmiştir. Bu inceleme ile immünhistokimyasal olarak ER, PgR, HER2 ve Ki67 boyamaları uygulanmış tümörler tespit edilerek 194 olgu çalışmaya dâhil edilmiştir.

Çalışma kapsamındaki vakalarda Ki67 immünhistokimyasal boyaması için eşik değer \%14 (5) olarak kabul edilmiştir. ER ve/veya PgR(+)/HER2(-)/Ki67 s \% 14 profile sahip tümörler Luminal $A$, ER ve/veya $\mathrm{PgR}(+) / \mathrm{HER} 2(+)$ veya (-) /Ki67 > \%14 tümörler Luminal B, ER(-)/PgR(-)/HER2(+) tümörler HER2 overeksprese tip ve $\mathrm{ER}(-) / \mathrm{PgR}(-) / \mathrm{HER} 2(-)$ tümörler ise TNMK olarak sınıflandırıldı. Rutin inceleme sırasında CK5/6 veya EGFR boyamaları yalnızca bazı tümörlere yapıldığı için bazal benzeri fenotipe sahip olan tümörler kesin olarak belirlenememiş ve TNMK olarak değerlendirilmiştir. Belirlenen moleküler alt tiplerin yaş, histolojik derece, lenfovasküler invazyon, tümör çapı, aksiller lenf nodu metastazı gibi klinikopatolojik özelliklerle ilişkisi araştırılmıştır.

İstatistik analiz SPSS for Windows programı kullanılarak Spearman Korelasyon, Ki-kare, Kruskal-Wallis ve Mann Whitney U testleri ile gerçekleştirildi. $p<0.05$ değeri istatistiksel olarak anlamlı kabul edilmiştir.

\section{Bulgular}

Beş yıllık arşivimizde immünhistokimyasal olarak moleküler alt tipleri belirlenebilen 194 invaziv meme karsinomu olgusu tespit edildi. Ortalama yaş 54,89 (25-86) olarak belirlendi. Hastalar yaş aralığına göre değerlendirildiğinde; yaşı $\leq 40$ olan $25(\% 12,9)$ olgu, $41-60$ arası olan $100(\% 51,5)$ olgu ve $>60$ olan 69 $(\% 35,6)$ olgu saptandı. Tümörler Modifiye Bloom-Richardson Derecelendirme Sistemine göre sınıflandırıldığında; $45(\% 23,2)$ olgu derece $1,85(\% 43,8)$ olgu derece 2, 64 (\%33) olgu ise derece 3 olarak izlendi. Tümör derecesinin yaşa göre dağılımı Tablo 1'de özetlendi. 
Patolojik T evrelemesine göre olgular değerlendirildiğinde; $70(\% 36,1)$ olgu pT1, $99(\% 51)$ olgu pT2 ve $22(\% 11,3)$ olgu ise pT3 olarak saptandı. Tümörler, $110(\% 56,7)$ olguda sol, $84(\% 43,3)$ olguda ise sağ memede lokalize idi. İnvaziv meme karsinomu olgularında ER ve PgR dağılımları; ER+/ PgR+ \%67,2, ER-/ PgR- \%24, ER+/PgR- \%6 ve ER-/PgR+ \%2,7 olarak tespit edildi (Tablo 2).

Tümörlerin moleküler alt tipleri sırasıyla $92(\% 47,4)$ olguda Luminal A, $50(\% 25,8)$ olguda Luminal B, 26 $(\% 13,4)$ olguda HER2 overeksprese tip ve $26(\% 13,4)$ olguda TNMK idi. $77(\% 39,7)$ olguda lenfovasküler invazyon, $108(\% 55,7)$ olguda aksiller lenf nodu metastazı gözlendi. Tümörler histolojik alt tip olarak değerlendirildiğinde ise $143(\% 73,7)$ olgu özel tip olmayan invaziv meme karsinomu, $22(\% 11,3)$ olgu invaziv lobüler karsinom, $29(\% 14,9)$ olgu mikst karsinom ve diğer özel tip karsinomlar olarak saptandı. 194 invaziv meme karsinomu olgusunun klinikopatolojik özellikleri Tablo 3'te özetlendi.

Çalışmamız kapsamındaki hormon reseptörlerinin ilişkileri değerlendirildiğinde, ER ile PgR arasında pozitif korelasyon, Ki67 ile ER ve PgR arasında ise negatif korelasyon saptandı $(p<0,001)$. Hormon reseptörleri ve Ki67'nin tümör derecesi ile ilişkileri değerlendirildiğinde ise ER ve PgR'nin düşük tümör derecesi ile, yüksek Ki67'nin ise yüksek tümör derecesi ile iliş̧ili olduğu belirlendi ( $p<0,001)$.

Ki67'nin klinikopatolojik parametreler ile ilişkisi incelendiğinde Ki67 ile lenfovasküler invazyon varlığı, aksiller lenf nodu metastazı varlığı, ileri pN evresi ve büyük tümör çapı arasında anlamlı ilişki saptandı $(p<0,05)$.

Luminal B tümörler, HER2 overeksprese ve triple negatif tümörlerde; Luminal A tümörlere göre tümör çapı $(p=0,022)$ istatistiksel olarak anlamlı bir şekilde daha büyük saptandı. Benzer şekilde, tümör derecesi Luminal $B, H E R 2$ overeksprese ve triple negatif tümörlerde Luminal A tümörlere göre daha yüksek $(p<0,0001)$ izlendi.

Luminal tip tümörlerle karşılaştırıldığında, HER2 overeksprese ve triple negatif tümörlerde lenfovasküler invazyon oranı anlamlı olarak daha fazla $(p<0,0001)$ idi. Luminal B tümörlerde ise lenfovasküler invazyon, Luminal A tümörlere göre daha fazla $(p<0,001)$ düzeyde belirlendi. Luminal A tümörlerle karşılaştırıldığında Luminal B, HER2 overeksprese ve triple negatif tümörlerde aksiller lenf nodu metastaz varlığı anlamlı olarak daha yüksekti $(p<0,0001)$. Ayrıca pN evresi Luminal B, HER2 overeksprese ve triple negatif tümörlerde, Luminal A tümörlere göre istatistiksel olarak anlamlı $(p<0,05)$ düzeyde daha ileri bulundu.

\section{Tablo 1 Tümör derecesinin yaşa göre dağılımı}

\begin{tabular}{|c|c|l|l|l|c|}
\hline \multicolumn{2}{|c|}{} & \multicolumn{3}{c|}{ Tümör Derecesi } & Toplam \\
\cline { 2 - 6 } & Derece 1 & Derece 2 & Derece 3 & 25 \\
\hline \multirow{3}{*}{ Yaş } & $\leq 40$ & $3(\% 6,7)$ & $8(\% 9,4)$ & $14(\% 21,9)$ & 100 \\
\cline { 2 - 6 } & $41-60$ & $29(\% 64,4)$ & $41(\% 48,2)$ & $30(\% 46,9)$ & 69 \\
\hline
\end{tabular}

\begin{tabular}{|c|c|c|c|}
\hline & & \multicolumn{2}{|c|}{ PgR } \\
\hline & & Yok $(n=55)$ & $\operatorname{Var}(n=128)$ \\
\hline \multirow{2}{*}{ ER } & Yok $(n=49)$ & $44(\% 24)$ & $5(\% 2,7)$ \\
\hline & $\operatorname{Var}(n=134)$ & $11(\% 6)$ & $123(\% 67,2)$ \\
\hline
\end{tabular}




\begin{tabular}{|c|c|}
\hline Ortalama yaş $(n=194)$ & $54,89(25-86)$ \\
\hline \multicolumn{2}{|l|}{ Moleküler alt tip (n=194) } \\
\hline Luminal A & $92(\% 47,4)$ \\
\hline Luminal B & $50(\% 25,8)$ \\
\hline HER2 overeksprese & $26(\% 13,4)$ \\
\hline Triple negatif & $26(\% 13,4)$ \\
\hline \multicolumn{2}{|l|}{ Histolojik alt tip ( $n=194)$} \\
\hline İnvaziv meme karsinomu, NST & $143(\% 73,7)$ \\
\hline İnvaziv lobüler karsinom & $22(\% 11,3)$ \\
\hline Mikst karsinom ve diğer & $29(\% 14,9)$ \\
\hline \multicolumn{2}{|l|}{ Lenfovasküler invazyon ( $\mathrm{n}=194)$} \\
\hline Yok & $117(\% 60,3)$ \\
\hline Var & $77(\% 39,7)$ \\
\hline \multicolumn{2}{|l|}{ Aksiller metastaz $(n=187)$} \\
\hline Yok & $79(\% 40,7)$ \\
\hline Var & $108(\% 55,7)$ \\
\hline \multicolumn{2}{|l|}{ Histolojik derece $(n=194)$} \\
\hline 1 & $45(\% 23,2)$ \\
\hline 2 & $85(\% 43,8)$ \\
\hline 3 & $64(\% 33)$ \\
\hline \multicolumn{2}{|l|}{ Tümör çapı (n=191) } \\
\hline$\leq 2 \mathrm{~cm}$ & $70(\% 36,1)$ \\
\hline $2-5 \mathrm{~cm}$ & $99(\% 51)$ \\
\hline$>5 \mathrm{~cm}$ & $22(\% 11,3)$ \\
\hline
\end{tabular}

\section{Tartışma}

Meme kanserinin moleküler biyolojisi üzerine yapılan son on yıldaki çalışmalar ve elde edilen veriler, hastaıığın moleküler açıdan sınıflandırılmasını sağlamıştır. Moleküler belirteçlerin konvansiyonel meme kanseri sınıflandırma sistemlerine dâhil edilmesi, tedavinin daha etkili bir şekilde yönlendirilmesine ve yeni tedavilerin geliştirilmesi için potansiyel hedeflerin araştırılmasına imkân vermiştir (6). Histolojik tip, TNM evresi ve Nottingham Histolojik Derecelendirme Sistemi meme kanseri için geleneksel prognostik araçlardır. Ayrıca, meme kanserinin immünhistokimyasal moleküler sınıflandırmasının farklı nüks riskleri taşıyan hastaları tanımlayabildiği ve kanser tedavisine ilişkin öngörü sağladığı da bildirilmiştir (7).
Tenea-Cojan ve ark. (8) kendi serilerinde özel tip olmayan invaziv meme karsinomunu \%63,37 düzeyinde izlediklerini bunu invaziv lobüler karsinomun \%10,56 ile izlediğini bildirmişlerdir. Bu bulgularla uyumlu olarak serimizde yer alan tümörlerin $\% 73,7$ ile büyük çoğunluğunu özel tip olmayan invaziv meme karsinomu, \%11,3'ünü ise invaziv lobüler karsinom oluşturmaktadır. Ayrıca literatürle uyumlu olarak çalışmamızda tümörlerin en çok 20-50 mm aralığında çapa sahip olduğu (\%51), \%36,1'inin 20 mm'den küçük çapta olduğu, \%11,3'ünün 50 mm'den büyük çapa sahip olduğunu gözlemledik (8). Aksiller lenf nodu metastazı varlığı açısından ise literatürde bildirilenden $(\% 47,8)$ daha yüksek bir oran $(\% 55,7)$ tespit edildi $(8)$.

Meme tümörlerinin derecelendirmesi değerlendirildiğinde literatür ile uyumlu olarak; bu çalışmada da derece 2 tümörler daha fazla $(\% 43,8)$ izlendi $(9,10)$. 
Bunu derece 3 (\%33) ve derece $1(\% 23,2)$ tümörler takip etti. Bu çalışmada $\mathrm{ER}, \mathrm{PgR}$ pozitifliği ile düşük tümör derecesi ve yüksek Ki67 ile yüksek tümör derecesi arasında kuvvetli ilişki saptandı $(p<0,001)$.

$\mathrm{Bu}$ çalışma ile elde edilen hormon reseptörlerinin karşılıklı ilişkileri değerlendirildiğinde $\operatorname{ER}(+) / \operatorname{PgR}(+)$ $\% 67,2$, ER(-)/PgR(-) \%24, ER(+)/PgR(-) \%6 ve ER()$/ \operatorname{PgR}(+) \% 2,7$ değerlerinin elde edildiği ve $\mathrm{ER}(+) /$ $\mathrm{PgR}(+)$ profilin en yüksek oranda bulunduğu görülmektedir. Bu husus Chu ve ark. (11) tarafından ve literatürde yaygın olarak bildirilen veriler ile uyumludur. Söz konusu araştırıcılar kendi çalışmalarında da en fazla olgunun $\mathrm{ER}(+) / \mathrm{PgR}(+)$ profile sahip (\%63.9) olduğunu bildirmişlerdir (11). Ayrıca çalışmamızda ER ve PgR arasında kuvvetli $(p<0,001)$ pozitif korelasyon saptandı.

Kamranzadeh ve ark. (12) Ki67 için >10\% eşik değerini kullanarak elde ettikleri verileri değerlendirdiklerinde; Ki67 ile hormonal reseptörler ve HER2 gibi bazı prognostik faktörler arasında anlamlı bir ilişki olmadığını ve Ki67'yi invaziv meme kanseri için bağımsız bir prognostik faktör olarak kullanamadıklarını bildirmişlerdir (12). Ancak bu çalışmada Ki67 için > \%14 değeri baz alınmış ve yüksek Ki67 ile ER ve PgR arasında kuvvetli negatif korelasyon saptanmıştır $(p<0,001)$. Ayrıca yüksek Ki67 ile lenfovasküler invazyon varlığı, aksiller lenf nodu metastazı varlığı, ileri pN evresi, büyük tümör çapı arasında anlamlı $(p<0,05)$ ilişkiler saptandı.

Meme kanserinde Luminal A ve Luminal B alt tiplerinin doğru olarak sınıflandırılmasının, tedavinin belirlenmesinde önemli olduğu bildirilmektedir (13). Literatür ile uyumlu olarak; çalışmamızda Luminal A tipi en sık $(\% 47,4)$ görülmüştür $(10,14)$. Ayrıca literatürde bildirildiği gibi bizim serimizde de Luminal B tümörler Luminal A tümörlere göre daha agresif histopatolojik özelliklere sahipti.

Garrido-Castro ve ark. (15) TNMK'lerin diğer meme kanseri alt tipleri ile karşılaştırıldığında daha yüksek nüks oranları, daha büyük metastaz potansiyeli ve daha kısa genel sağ kalım ile karakterize olduğunu bildirmişlerdir $(15,16)$. İmmünhistokimyasal olarak triple negatif olan tümörler, moleküler alt tip olan ve immünhistokimyasal bazal hücre belirteçleri ile pozitif boyanan bazal benzeri fenotipi tam olarak temsil etmemekle birlikte bu fenotiple örtüşmektedir. Serimizde immünhistokimyasal olarak TNMK oranı $\% 13,4$ olup bu tümörler agresif histopatolojik özelliklere sahiptir.

HER2 overeksprese alt tipinin incelendiği bir çaIışmada; ileri $\mathrm{pN}$ evresi ve uzak metastaz varlığı ile
HER2 overekspresyonu arasında istatistiksel olarak anlamlı ilişki tespit edilerek; HER2 overekspresyonunun meme kanserinde en önemli prognostik faktörlerden biri olduğu ileri sürülmüştür (17). Çalışmamızda HER2 overeksprese tipin, Luminal A tipine göre tümör derecesi bakımından daha agresif olduğu ve istatistiksel olarak anlamlı fark bulunduğu saptandı. Tümörler pN bakımından değerlendirildiğinde ise; Luminal $B$ ve HER2 overeksprese alt tiplerde, Luminal A'ya göre pN evresinin daha ileri olduğu tespit edildi.

Sonuç olarak, Luminal B tümörlerin Luminal A tümörlere göre daha agresif histopatolojik özellikler sergilemekte olduğu, TNMK'nin agresif histopatolojik özelliklere sahip olduğu, Luminal B, TNMK ve HER2 overeksprese alt tiplerde Luminal A'ya göre pN evresinin daha ileri olduğu tespit edildi. Bu sonuçlar değerlendirildiğinde ER, PgR, HER2 ve Ki67 immünhistokimyasal boyamaları kullanılarak yapılan moleküler alt tiplendirmenin hasta yönetiminde avantaj sağlamaya devam edeceği sonucuna varılmıştır.

\section{Kaynaklar}

1. Petersen NV, Ramskov S, Andersen RS, Met Ö, Straten PT, Bentzen AKK, et al. T-cell recognition of breast cancer antigens. Proceedings of the 4 th CRI-CIMT-EATI-AACR International Cancer Immunotherapy Conference: Translating Science into Survival; Sept 30-Oct 3, 2018; New York, NY. Philadelphia (PA): AACR; Cancer Immunol Res 2019;7(2):Ab.nr B036.

2. Desmedt C, Haibe-Kains B, Wirapati P, Buyse M, Larsimont D, Bontempi G, et al. Biological processes associated with breast cancer clinical outcome depend on the molecular subtypes. Clin Cancer Res 2008;14(16):15.

3. Prat A, Pineda E,Adamo B, Galván P, Fernández A, Gaba L, et al. Clinical implications of the intrinsic molecular subtypes of breast cancer. Breast 2015;24(2):26-35.

4. Dias K, Dvorkin-Gheva A, Hallett RM, Wu Y, Hassell J, Pond GR, et al. Claudin-Low Breast Cancer; Clinical \& Pathological Characteristics. PLoS One. 2017;12(1):e0168669

5. Goldhirsch A, Wood WC, Coates AS, Gelber RD, Thürlimann $B$, Senn HJ. Strategies for subtypes-dealing with the diversity of breastcancer: highlights of the St Gallen international expert consensus on the primary therapy of early breast cancer 2011. Annals of Oncology 2011;22:1736-1747.

6. Yersal O, Barutca S. Biological subtypes of breast cancer: Prognostic and therapeutic implications. World J Clin Oncol. 2014;5(3):412-424.

7. Ni YB, Tsang JY, Chan SK, Tse GM. A novel morphologic-molecular recurrence predictive model refines traditional prognostic tools for invasive breast carcinoma. Ann Surg Oncol. 2014;9:2928-2933

8. Tenea-Cojan TS, Georgescu CV, Corici OM, Voinea B, Georgescu DM, Vidrighin C, et al. Histopathological study on conservatively operated breast carcinomas. Curr Health Sci J. 2016;42(3):269-282.

9. Jönsson G, Staaf J, Vallon-Christersson J, Ringnér M, Holm K, Hegardt C, et al. Genomic subtypes of breast cancer identified by array-comparative genomic hybridization display distinct molecular and clinical characteristics. Breast Cancer Res. 2010;12(3):R42.

10. Cherbal F, Gaceb H, Mehemmai C, Saiah I, Bakour R, Rouis $A O$, et al. Distribution of molecular breast cancer subtypes 
among Algerian women and correlation with clinical and tumor characteristics: a population-based study. Breast Dis. 2015;35(2):95-102.

11. Chu KC, Anderson WF, Fritz A, Ries LA, Brawley OW. Frequency distributions of breast cancer characteristics classified by estrogen receptor and progesterone receptor status for eight racial/ethnic groups. Cancer 2001;1:37-45.

12. Kamranzadeh H, Ardekani RM, Kasaeian A, Sadighi S, Maghsudi S, Jahanzad I, et al. Association between Ki-67 expression and clinicopathological features in prognosis of breast cancer: A retrospective cohort study. J Res Med Sci 2019;24:30.

13. Nishimukai A, Yagi T, Yanai A, Miyagawa Y, Enomoto Y, Murase $\mathrm{K}$, et al. High Ki-67 Expression and low progesterone receptor expression could independently lead to a worse prognosis for postmenopausal patients with estrogen receptor-positive and HER2-negative breast cancer. Clin Breast Cancer 2015;15(3):204-211.

14. Caldarella A, Buzzoni C, Crocetti E, Bianchi S, Vezzosi V, Apicella $\mathrm{P}$, et al. Invasive breast cancer: a significant correlation between histological types and molecular subgroups. J Cancer Res Clin Oncol 2013;139(4):617-623.

15. Garrido-Castro AC, Lin NU, Polyak K. Insights into Molecular Classifi cations of Triple-Negative Breast Cancer: Improving Patient Selection for Treatment, American Association for Cancer Research, 2019;doi: 10.1158/2159-8290.CD-18-1177

16. Van Calster B, Vanden Bempt I, Drijkoningen M, Pochet N, Cheng J, Van Huffel S, et al. Axillary lymph node status of operable breast cancers by combined steroid receptor and HER2 status: triple positive tumours are more likely lymph node positive. Breast Cancer Res Treat 2009;113(1):181-187.

17. Kim MJ, Ro JY, Ahn SH, Kim HH, Kim SB, Gong G. Clinicopathologic significance of the basal-like subtype of breast cancer: a comparison with hormone receptor and Her2/neu-overexpressing phenotypes. Hum Pathol 2006;37(9):1217-1226. 